\title{
METODOLOGIAS LÚDICAS NA PREVENÇÃO DA ESQUISTOSSOMOSE E OUTRAS DOENÇAS PARASITÁRIAS EM ESCOLAS PÚBLICAS DA BAHIA - RELATO DE EXPERIÊNCIA
}

Camila Pereira

\begin{abstract}
Resumo: No município de Jequié, a esquistossomose é considerada um problema de saúde pública. Na criança causa um impacto na nutrição, desenvolvimento intelectual e somático. As atividades lúdicas podem facilitar o processo de ensino-aprendizagem e ainda serem prazerosas, interessantes e desafiantes. Este trabalho faz parte de um projeto de extensão contínuo que se iniciou em 2003 com os objetivos de ensinar a prevenção das parasitoses em escolas públicas usando atividades lúdicas, e levar informação sobre a prevenção aos familiares. Para alcançarmos os objetivos, discentes dos cursos de enfermagem, odontologia e biologia da UESB ministraram oficinas educativas, enquanto cursaram a disciplina Parasitologia Humana. Uma série de atividades lúdicas foi aplicada durante as oficinas educativas. Como procedimento avaliativo utilizou-se: desenhos, massa de modelar, gincanas entre outros recursos. Para prestar esclarecimentos aos pais das crianças e adolescentes sobre a prevenção das parasitoses foram realizadas reuniões nas escolas e visitas domiciliares. Percebeu-se pelos alunos, fato confirmado através: das observações diretas, de diálogos em sala de aula, análises de questionários, do conteúdo dos desenhos e massas de modelar, que os principais aspectos a respeito das transmissões e prevenções das parasitoses foram bem compreendidos pela maioria dos escolares. Foram realizados exames coprológicos dos escolares. Neste estudo, destacou-se a elevada frequência da esquistossomose (22\%), seguida da ascaridíase $(14,7 \%)$, tricuríase $(11,8 \%)$. Nos protozoários, o índice encontrado foi de $10,2 \%$ para amebíase e $8,0 \%$ para giardíase. Os parasitados foram encaminhados ao atendimento médico na própria escola ou orientados a procurarem um posto de saúde para o tratamento específico.
\end{abstract}

Palavras-chave: escolares. esquistossomose. lúdico. parasitoses. prevenção.

\section{Introdução}

\section{A Importância do lúdico na educação}

Os métodos lúdicos são formas de manejar experiências, criar situações para dominar à realidade e experimentá-la. Segundo Teles (1999) brincar se coloca num patamar importantíssimo para a felicidade e realização da criança, no presente e no futuro. Brincando, ela explora o mundo, constrói o seu saber, aprende a respeitar o outro, desenvolve o sentimento de grupo, ativa a imaginação e se autorrealiza.

O brincar estimula a criatividade, a imaginação, aprofunda, para a criança, a compreensão da realidade. Se considerarmos que as atividades lúdicas e o humor colocam o indivíduo em estado criativo. Entretanto, se a brincadeira que estimula a criatividade só pode florescer num do Departamento de Ciências Biológicas, e-mail: milaperefraga@gmail.com, Apoio financeiro: UESB.

Discentes do curso de Enfermagem da UESB/Jequié-BA. 
ambiente de liberdade e flexibilidade psicológicas, de busca de prazer, de autorrealização, devese concluir que o desenvolvimento daquela se encontra profundamente vinculado aos objetivos educacionais.

As atividades lúdicas podem facilitar o processo de ensino-aprendizagem e ainda serem prazerosas, interessantes e desafiantes. O jogo educativo pode ser um ótimo recurso didático ou estratégia de ensino para os educadores e também ser um rico instrumento para a construção do conhecimento.

\section{A Esquistossomose em Jequié}

No município de Jequié, a esquistossomose está entre as parasitoses de grande prevalência, constituindo um desafio para a saúde pública. A história da esquistossomose em Jequié está intimamente relacionada com a presença de lagoas e rios que cortam a cidade, sendo o "Rio das Contas" o principal da região. A infecção parasitária é quase sempre negligenciada. Os indivíduos permanecem parasitados de forma silenciosa por longos anos, o que causa sérios problemas principalmente nas crianças, nas quais a evolução da infecção pode determinar desde quadros assintomáticos até falta de apetite, emagrecimento, diarreias e em alguns casos até óbitos se não for tratada (Quadros, 2004, Uchôa, 2009).

As parasitoses intestinais são mais prevalentes em populações de nível socioeconômico mais baixo e com condições precárias de saneamento básico e principalmente a falta de informação sobre a prevenção, sendo as crianças em idade escolar as mais acometidas (Ramos, 2006). A esquistossomose na criança causa um impacto considerável na nutrição, crescimento e no desenvolvimento intelectual (Guimarães, 2006). No Brasil, a faixa etária de maior prevalência da esquistossomose abrange dos seis aos vinte anos. O contato mais assíduo dos jovens com as águas em atividades recreativas pode explicar tal predisposição. Por isso, o segmento infantojuvenil, dos sete aos quatorze anos de idade, foi adotado como parâmetro operacional para as atividades de controle no Brasil (Ferreira, 2000). Considerando que crianças e adolescentes geralmente frequentam alguma escola de ensino fundamental, e sabe-se que existe uma lacuna de informação sistemática adequada sobre as parasitoses, enfatizando a esquistossomose. Apenas no sétimo ano do ensino fundamental é incluído o ensino de doenças 
parasitárias. Portanto, não se leva em conta as faixas etárias menores (6 aos 12 anos) que estão vulneráveis a contrair tais doenças, devido as condições socioeconômicas precárias e faltam-lhes informações adequadas. Outro agravante é a falta de atenção específica para o ensino sobre doenças que são endêmicas na circunvizinhança das escolas públicas de periferia.

Este relato de experiência faz parte do projeto de extensão contínuo intitulado "Profilaxia de Doenças Parasitárias" que se iniciou em 2003.

\section{Objetivos}

\section{Objetivos gerais}

Este projeto de extensão tem como objetivo a educação na prevenção da esquistossomose e outras parasitoses usando métodos lúdicos em escolas públicas.

\section{Objetivos específicos}

- Colocar em prática os conhecimentos que os discentes adquirem na disciplina Parasitologia Humana.

- Promover parceria Universidade-Comunidade atuando na qualidade de vida.

- Promover oficinas educativas e palestras estimulando os discentes à socialização do saber.

- Ensinar sobre os parasitas e mostrar as formas de prevenção aos escolares públicos e familiares.

- Coletar amostras fecais para exames parasitológicos

- Determinar a frequência das enteroparasitoses dos escolares

- Encaminhar os parasitados ao tratamento específico

\section{Materiais e Métodos}

\section{Local de estudo e Amostra}

As escolas municipais "Celi de Freitas" e "Dr. Joel Coelho de Sá - CAIC” de Jequié foram escolhidas para a realização do presente trabalho devido ao fato de atenderem uma clientela de baixa renda. O público alvo foi composto de 1.382 escolares de faixa etária entre 6 a 19 anos matriculados em turmas desde alfabetização até $8^{\circ}$ ano do ensino fundamental, nos anos de 2003 a 2010. Os discentes dos cursos de enfermagem, odontologia e biologia, da UESB campus de Jequié-BA, que cursaram a disciplina Parasitologia Humana participaram do projeto voluntariamente e ministraram oficinas educativas nas escolas. Nos encontros semanais com duração de uma hora durante um semestre foram enfocadas as necessidades básicas de higiene corporal, bucal, cuidados com a água, alimentos, preservação do meio ambiente, e prevenção da esquistossomose, ancilostomose, pediculose, ascaridíase entre outras doenças parasitárias. do Departamento de Ciências Biológicas, e-mail: milaperefraga@gmail.com, Apoio financeiro: UESB.

Discentes do curso de Enfermagem da UESB/Jequié-BA. 
Os discentes voluntários foram divididos em grupos de 5 a 8 componentes e atuaram em salas de aula das escolas citadas. Habitualmente atuamos em 4 salas de aula em média simultaneamente por semestre, e se repete a cada semestre com novos discentes e novas turmas de escolares.

\section{Oficinas Educativas nas Escolas}

No primeiro encontro com os escolares, os discentes da UESB se fantasiam com o intuito de cativar as crianças e dinâmicas de apresentação e entrosamento são realizadas.

Nos encontros seguintes iniciaram-se os assuntos específicos citados utilizando-se de uma série de atividades lúdicas, entre elas podemos citar: representações teatrais, desenho animado educativo, músicas, paródias, teatro de fantoches, etc. Os escolares participaram ativamente das oficinas educativas através de confecção de cartazes, desenhos e pinturas, jogos, brincadeiras, danças, cantos, entre outras atividades.

A leitura das estórias da coleção CIRANDA DA SAÚDE (Shall, 1986) foi utilizada para introduzir vários temas abordados. Nas oficinas sobre a prevenção da esquistossomose foram utilizadas várias atividades lúdicas, entre elas podemos citar: a leitura do livro "Feitiço da Lagoa", representação teatral, exibição do documentário sobre a esquistossomose- filmado em Jequié, explicação do ciclo do Shistosoma mansoni usando os elementos emborrachados, entre outros recursos.

O personagem Jeca Tatu, de Monteiro Lobato, foi usado para introduzir o problema da ancilostomose. Na representação teatral foi enfatizada a necessidade de andar sempre calçado, ir ao médico, fazer exame de fezes e tratamento específico.

A preservação do meio ambiente foi enfocada e várias atividades foram desenvolvidas, como exemplo: ensinar a confecção de brinquedo com garrafa PET, entre outras. A representação teatral sobre a pediculose mostrou com se livrar dos piolhos e um microscópio óptico foi levado para a visualização do "piolho da cabeça".

O teatro de fantoches foi um recurso lúdico bastante usado nos diversos assuntos devido à grande aceitação pelas crianças.

Nas últimas semanas foram aplicadas atividades lúdicas avaliativas usando atividades de recorte, colagem e pintura, massa de modelar, caça palavra, questionários, palavras cruzadas, jogos educativos - "Perfil Parasitológico" (desenvolvido baseado no jogo comercial "Perfil I, II, III e IV"), entre outras.

Universidade Estadual do Sudoeste da Bahia - UESB, Pós-Doutorado, Professora Plena do Departamento de Ciências Biológicas, e-mail: milaperefraga@ gmail.com, Apoio financeiro: UESB.

Discentes do curso de Enfermagem da UESB/Jequié-BA. 
O encerramento das oficinas educativas acontece no auditório das escolas juntando as salas que estavam participando. Os discentes voluntários apresentam uma dramatização teatral com fantoches e um resumo dos principais temas abordados é apresentado com a interação das crianças no final do espetáculo. A despedida acontece em sala de aula com brincadeiras, festinha e distribuição de presentes.

\section{Palestras para os pais e familiares nas escolas}

Durante o semestre aconteceram as reuniões com os pais das crianças nas escolas com o intuito de esclarecer sobre a prevenção das doenças parasitárias. São realizadas palestras enfatizando a prevenção da esquistossomose e das outras parasitoses intestinais. Durante as reuniões são oferecidos coletores para realização de exames coprológicos dos escolares juntamente com a autorização dos pais. E são distribuídos kits de higiene pessoal e bucal.

\section{Visitas Domiciliares realizadas pelos discentes aos familiares dos escolares}

As visitas domiciliares foram realizadas pelos discentes da UESB com o mesmo objetivo de levar conhecimento aos familiares sobre a prevenção da esquistossomose e outras parasitoses. Foram usados folhetos ilustrativos para as explicações das parasitoses.

\section{Exames parasitológicos de fezes}

Foi firmada uma parceria com a $13^{\mathrm{a}}$ DIRES que realizaram os exames parasitológicos de fezes dos escolares utilizando a metodologia de sedimentação espontânea. Esta parceria se iniciou em agosto de 2003 e encerrou em 2007. Uma nova parceria com a Escola Politécnica Humberto Reis foi iniciada no início de 2009 até agosto de 2010.

\section{Resultados}

\section{Das oficinas educativas}

O ensino interativo através de várias atividades didáticas pedagógicas de caráter lúdico desenvolvidas nos encontros semanais foi de grande aproveitamento. Após um semestre de trabalho, podemos notar através da avaliação das atividades aplicadas que a grande maioria dos escolares aprendeu corretamente a prevenção e o ciclo de vida do Schistosoma, além da prevenção das outras parasitoses trabalhadas. Pode-se evidenciar que os escolares assimilaram o conteúdo e têm-se a expectativa de que com esse aprendizado eles possam melhorar sua condição de vida quando formarem suas respectivas famílias.

\section{Dos exames parasitológicos de fezes}

Universidade Estadual do Sudoeste da Bahia - UESB, Pós-Doutorado, Professora Plena do Departamento de Ciências Biológicas, e-mail: milaperefraga@ gmail.com, Apoio financeiro: UESB.

Discentes do curso de Enfermagem da UESB/Jequié-BA. 
Das 626 amostras analisadas até o momento, 58,5\% apresentaram algum tipo de parasito intestinal. Destaca-se que 57,3\% dos escolares parasitados apresentaram poliparasitismo. Dentre os parasitos, o Schistosoma masnsoni apresentou o maior índice com 22\%, seguido da ascaridíase $14,7 \%$, tricuríase $11,8 \%$, entre outros. Nos protozoários, o índice encontrado foi de $10,2 \%$ para amebíase e 8,0\% para giardíase.

Os escolares que apresentaram resultados positivos para um ou mais parasitas foram encaminhados ao pediatra da própria escola ou os pais foram orientados a procurarem um posto de saúde.

\section{Discussão e Conclusões}

A implementação de infraestrutura sanitária é fundamental para redução da prevalência dos enteroparasitos, mas o resultado não é eficaz se não houver juntamente com essas medidas mudanças comportamentais, sendo que estas se adquirem por meio da informação, assim práticas educacionais levam os escolares e familiares a adquirirem conhecimento e este é fundamental na prevenção de doenças.

Este trabalho está levando informação e esclarecimento a respeito da esquistossomose e outras doenças parasitárias aos escolares e familiares; proporcionando realização de exames coprológicos e encaminhamento ao tratamento dos parasitados. Portanto, esse estudo torna-se de grande valia para a sociedade, principalmente em regiões onde existe uma grande parcela da população que vive em péssimas condições de habitações e sem formação educacional.

\section{Referências Bibliográficas}

Ferreira UM, Ferreira CS, Monteiro CA. Tendência secular das parasitoses intestinais na infância na cidade de São Paulo (1984-1996). Rev Saúde Pública 34:1-16, 2000.

Guimarães ICS, Tavares-Neto J. Transmissão urbana de esquistossomose em crianças de um bairro de Salvador, Bahia. Rev Soc Bras Med Trop; 39:451-455, 2006.

Quadros RM, Marques S, Arruda AAR, Delfes PSWR, Medeiros IAA. Parasitoses Intestinais em centros de educação infantil municipais de Lages, SC, Brasil. Rev Soc Bras Med Trop. 37:422423, 2004.

Universidade Estadual do Sudoeste da Bahia - UESB, Pós-Doutorado, Professora Plena do Departamento de Ciências Biológicas, e-mail: milaperefraga@gmail.com, Apoio financeiro: UESB.

Discentes do curso de Enfermagem da UESB/Jequié-BA. 
Shall, VT. O feitiço da Lagoa. Série Ciranda da Saúde, Antares, Rio de Janeiro, 1986.

Uchôa, CMA, Albuquerque, MC, Carvalho, FM, Falcão, AO, Silva, P. e Bastos, OMP. Parasitismo Intestinal em crianças e funcionários de creches comunitárias na cidade de NiteróiRJ, Brasil. Vol. 38(4): 267-278, 2009.

Résumé: Dans la ville de Jequié, lesquistossomose est considere um problème de santé publique. Les activités ludiques peuvent faciliter le processus de enseignement et d'apprentissage et encore furent agréables, intéressantes et provocatrices. Ce travail fait partie d'un projet d'extension continu qui s'est initiée dans 2003, avec les objectifs d'enseigner prévention des "parasitoses" dans des écoles publiques; et divulguer des informations sur la prévention aux parents. Nous pour atteindre les objectifs, les élèves du cours de métier d'infirmier, odontologie et biologie de l'UESB ont donné des cours éducatifs, tant qu'ils étudient la discipline Parasitologie Humaine. Une série d'activités ludiques a été appliquée pendant les cours éducatifs. Comme procedure d'évaluation, ils ont été utilisés: dessins, masse former, activités récréatives et autres ressources. Pour expliquer aux parents des enfants ET dês adolescents sur La prévention dês "parasitoses" Il sont été faites dês réunions dans lês écoles et des visites domiciliaire. Il s'estperçu par lesélèvesleshabitudesconfirméesà traversdescommentairesdirects, de dialogues danssalle de leçon, analyses de questionnaires, ducontenudesdessins et dês masses former, que lês principaux aspects concernant lês transmissions et lês préventions dês "parasitoses" ils ont bien été compris par à la majorité dês étudiants. Ils ont été réalisés dês examens coprologiques dês écoliers. Dans cette étude, s'est détaché el'élevée fréquence de esquistossomose (22\%), suivante de l'ascaridiase (14.7\%), tricurose (11.8\%). Dans lês protozoaires, l'indice trouvé a été de $10.2 \%$ pour amebíase et $8,0 \%$ pour giardiase. Les parasites ont été conduits au service medical dans l'école elle-même ou guidés à chercherun grades de santé pour Le traitement spécifique.

Mots - clé: écoliers. esquistossomose. ludique. parasitoses. prévention.

Universidade Estadual do Sudoeste da Bahia - UESB, Pós-Doutorado, Professora Plena

do Departamento de Ciências Biológicas, e-mail: milaperefraga@gmail.com,

Apoio financeiro: UESB.

Discentes do curso de Enfermagem da UESB/Jequié-BA. 